\title{
Dementia and Diabetes Mellitus: Association with Apolipoprotein E4 Polymorphism from a Hospital in Southern India
}

\author{
Lakshmi Narayanan Kota, Bhagyalakshmi Mallapura Shankarappa, Prafulla Shivakumar, \\ Shilpa Sadanand, Bhavani Shankara Bagepally, Srinivas Brahmadevarahalli Krishnappa, \\ Meera Purushottam, Palanimuthu Thangaraju Sivakumar, Sanjeev Jain, Mathew Varghese, \\ and Srikala Bharath
}

Department of Psychiatry, National Institute of Mental Health and Neurosciences, Bangalore 560029, India

Correspondence should be addressed to Srikala Bharath, srikala.bharath@gmail.com

Received 14 December 2011; Accepted 7 April 2012

Academic Editor: Suvarna Alladi

Copyright ( 2012 Lakshmi Narayanan Kota et al. This is an open access article distributed under the Creative Commons Attribution License, which permits unrestricted use, distribution, and reproduction in any medium, provided the original work is properly cited. Objective. To evaluate the association of Apolipoprotein E4 (ApoE4) in Alzheimer's dementia (AD) with comorbid diabetes
mellitus (DM). Methods. The study included subjects with Alzheimer's dementia (AD) $(n=209)$, individuals with non-
Alzheimer's dementia (nAD) $(n=122)$, individuals with parental history of AD (f/hAD) $(n=70)$, and control individuals
who had normal cognitive functions and no parental history of dementia (NC) $(n=193)$. Dementia was diagnosed using
International Classification of Diseases-10 revision (ICD-10) criteria. DM was assessed on the basis of self-report and/or use
of antidiabetic medications. ApoE genotyping was done using sequence-specific primer polymerase chain reaction. Results. ApoE4
allele frequencies were highest among AD with comorbid DM $(0.35)$ followed by AD without DM $(0.25)$, nAD with DM $(0.13)$,
nAD without comorbid DM $(0.12)$, and NC $(0.08)$. Frequency of ApoE4 in persons with f/hAD was 0.13 . The association of AD
with co-morbid DM in ApoE4 carriers was more in comparison to NC with DM $(\mathrm{OR}=5.68, P=0.04)$. Conclusion. There is a
significant association between AD with co-morbid DM and ApoE4 genotype.

\section{Introduction}

With the rapid change in the demographic profile of India, the prevalence of chronic diseases of the elderly like dementia and DM type 2 is increasing. In India, over 3.7 million people aged 60 years and above suffer from dementia, predominantly of Alzheimer's type. Assuming that the current prevalence rate remains stable, these numbers are projected to increase to 6.35 million by 2025 [1]. Studies from India indicate that ApoE4 allele is significantly associated with $\mathrm{AD}$, and it is a risk factor [2-5].

There has been a pandemic rise of DM especially among Asian Indians. Currently 40.9 million Indians suffer from $\mathrm{DM}$, and this is projected to increase to 69.9 million by 2025 [6]. Genetic predisposition and environmental factors interact to increase the risk of DM among Asian Indians.
DM type 2 which accounts for $90 \%$ of DM is predominantly a polygenic disease with various loci identified at $P G C$ -

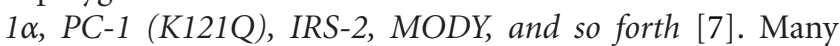
population-based cross-sectional studies [8] and prospective studies [9-13] have indicated that DM or abnormal glucose tolerance doubled the risk of $\mathrm{AD}$ ( $\mathrm{RR}$ 1.37-2.27); though others have not confirmed this link [14]. Tripathi et al. [15], in a study from Northern India, reported DM as a risk factor for dementia; $33.3 \%$ of their sample with dementia had diabetes compared to $9 \%$ of the controls $(P<0.001)$. Other reports from Asia confirm the association between $\mathrm{DM}$ and $\mathrm{AD}$ in ApoE4 carriers. Peila et al. [16] in a large population-based study of Japanese American men found a significant association between DM, AD, and ApoE4 carriers; subjects with ApoE4 allele and DM had a relative risk of 5.5 for AD. Matsuzaki et al. [17] in a retrospective analysis 
of autopsies found a very significant positive association between hyperglycaemia, AD neuropathology, and ApoE4 status (OR 38.9).

We conducted a hospital-based cross-sectional study of dementia, to evaluate the interaction between $\mathrm{AD}$ and diabetes, as a function of the ApoE4 allele status.

\section{Methods}

2.1. Sample. Consecutive persons with dementia attending the Geriatric Clinic of the Department of Psychiatry in National Institute of Mental Health and Neurosciences (NIMHANS), Bangalore, and their consenting offspring were invited to participate in this study. This sample is part of a larger study of genetic and clinical correlates in dementia, and details about evaluation have been reported earlier [2]. In this paper, the study sample $(n=594)$ included $\mathrm{AD}(n=$ $209)$, $\mathrm{nAD}(n=122), \mathrm{f} / \mathrm{hAD}(n=70)$, and NC $(n=193)$. The nAD group consisted of vascular and mixed dementia $(n=46)$, frontotemporal dementia $(n=30)$, Lewy body dementia $(n=10)$, and other dementias $(n=36)$. Control subjects included genetically unrelated and cognitively intact age-matched subjects. The study was approved by the Ethics Committee of NIMHANS, and informed consent was collected prior to participation. All the subjects were evaluated using a standard protocol including general clinical evaluation, functional assessment (Everyday Abilities Scale for India, EASI [18]), neuropsychology testing (Hindi Mental Status Examination, HMSE [19]), laboratory investigations (haemogram, blood glucose levels), and genotyping and imaging (MRI scans using a 1.5 or 3 Tesla machine; or CT scan) whenever possible. Clinical evaluation was done by trained psychiatric residents and the diagnosis of dementia established using ICD-10 criteria. Further sub-typing was done by a psychiatric/neurology consultant. Their comorbid DM was recorded based on laboratory results or selfreports, being on antidiabetic medication. Other participants were assessed using the same methodology and protocol.

Ten millilitres of venous blood was collected, and DNA was extracted using salting out method [20]. Polymerase chain reaction (PCR) was performed using sequence-specific primer PCR methodology [21]. The presence of 173-bp band was indicative of the specific ApoE haplotype. The results were corroborated with real-time PCR results for $10 \%$ of the samples in every experiment.

2.2. Statistical Methods. We compared ApoE4 frequency and $\mathrm{DM}$ status in $\mathrm{AD}, \mathrm{nAD}, \mathrm{f} / \mathrm{hAD}$, and NC. Statistical analysis was done using R software [22]. Comparisons between variables were done using chi-square test for categorical variables and unpaired $t$-test for continuous variables. Fisher's exact test was used when any of the values in the contingency table was less than 10 . Odds ratios and $P$ values were computed, and statistical significance was inferred if $P<0.05$.

\section{Results}

Based on the sample selection, $\mathrm{AD}, \mathrm{nAD}$, and the $\mathrm{NC}$ were older than 60 years $(61.14 \pm 11.40$ years; $61.73 \pm 12.41$ years;
$60.35 \pm 15.65$ years, resp.). The AD, $\mathrm{nAD}$, and NC group had crossed the age at risk for onset of DM. Results show that on average, $11.6 \%$ of our study group had developed DM. However, the prevalence of DM differed between the various groups, being- $17.7 \%$ of the $\mathrm{AD}, 13.9 \%$ of the $\mathrm{nAD}, 6.2 \%$ of the NC, and $4.3 \%$ of the $\mathrm{f} / \mathrm{hAD}$ (Table 1 ).

ApoE4 carrier rates in $\mathrm{AD}(n=98 / 209)$ were higher than age-matched NC $(n=32 / 193)(P<0.0001$, Table 1$)$. The difference in ApoE4 carrier status between $\mathrm{AD}$ with comorbid DM and NC was significant $(P=0.0001)$. ApoE4 allele frequencies were highest among $\mathrm{AD}$ with co-morbid $\mathrm{DM}(0.35)$ followed by $\mathrm{AD}$ without $\mathrm{DM}$ (0.25), $\mathrm{nAD}$ with DM (0.13), nAD without co-morbid DM (0.12), and NC (0.08). The association of $\mathrm{AD}$ with co-morbid DM in ApoE4 carriers was more in comparison to $\mathrm{NC}$ with $\mathrm{DM}(\mathrm{OR}=5.68$, $P=0.04$, Figure 1$)$.

There were 17 individuals in this study who were ApoE4 homozygotes-14 AD, $2 \mathrm{nAD}$, and one f/hAD. Among the 14AD with homozygous ApoE4, 6 (42.8\%) individuals were receiving treatment for DM. In comparison, there were 84 $\mathrm{AD}$ who were ApoE4 heterozygotes, of whom only 14 had DM (16.6\%). Homozygous ApoE4 carriers had significantly greater comorbidity of $\mathrm{DM}$ and $\mathrm{AD}(P=0.035)$.

\section{Discussion}

The present cross-sectional study evaluates the relationship between ApoE4 status, $\mathrm{AD}$ and $\mathrm{DM}$ in a sample from southern India. The study also confirms the significant association between ApoE4 allele and $\mathrm{AD}$ in the Indian population [2-5]. The ApoE4 frequency however was not associated with the age of onset of $\mathrm{AD}$, or the degree of cognitive and functional ability as assessed by HMSE and EASI.

The study also reiterates the increased association of $\mathrm{AD}$ and DM $(P=0.0004)$ established by other studies [ 8 $13,15]$. Interestingly, $A D$ individuals with $\mathrm{DM}$ were more likely to be ApoE4 carriers compared to NC with DM (OR 5.68). The ApoE4 allele frequency was also significantly high in this group (0.35). The current study indicates a need to evaluate the role of ApoE4 as a risk factor for DM in future. Earlier research of ApoE4 as a risk factor for DM has yielded inconsistent results. Study in Mexican Americans [23] did not find any difference in ApoE4 frequency between diabetics and nondiabetics. It is interesting to note that Xu et al. [10] found a significant association between borderline DM and $\mathrm{AD}$ only in non-ApoE4 carriers. Assessment of the ApoE4 status in DM without AD in the Indian population would be able to provide some clarity towards this. Individuals with ApoE4 allele if found to have an increased risk to DM in their middle age, the combined presence of ApoE4 and DM might further increase the risk of $\mathrm{AD}$ later. Testing of this hypothesis was not feasible in the present study as it was a cross-sectional one from a Geriatric Clinic which caters to the needs of elderly with dementia. A prospective controlled followup study of the individuals with DM with and without ApoE4 allele into old age is needed to establish the implications of this association of ApoE4, AD and DM. 
TABLE 1: Clinical profile and ApoE polymorphism in the study population.

\begin{tabular}{|c|c|c|c|c|c|c|}
\hline & $\begin{array}{c}\text { Alzheimer's } \\
\text { dementia (AD) } \\
(n=209)\end{array}$ & $\begin{array}{l}\text { Non-Alzheimer's } \\
\text { dementia (nAD) } \\
\quad(n=122)\end{array}$ & $\begin{array}{l}\text { Individuals with } \\
\text { parental history } \\
\text { of } \mathrm{AD}(\mathrm{f} / \mathrm{hAD}) \\
\quad(n=70)\end{array}$ & $\begin{array}{c}\text { Control } \\
\text { individuals with } \\
\text { no parental history } \\
\text { of dementia (NC) } \\
(n=193) \\
\end{array}$ & $\begin{array}{c}P \text { value } \\
\text { (comparing } \\
\mathrm{AD} \text { and } \mathrm{NC})\end{array}$ & $\begin{array}{c}P \text { value } \\
\text { (comparing } \\
\text { nAD and } \mathrm{NC})\end{array}$ \\
\hline Mean age in years & $61.14 \pm 11.40$ & $61.73 \pm 12.41$ & $37.27 \pm 8.87$ & $60.35 \pm 15.65$ & $0.56^{++}$ & $0.41^{++}$ \\
\hline $\mathrm{M}: \mathrm{F}$ & $105: 104$ & $75: 47$ & $51: 19$ & $114: 79$ & $0.076^{*}$ & $0.67^{*}$ \\
\hline $\mathrm{DM}, n(\%)$ & $37(17.7)$ & $17(13.9)$ & $3(4.3)$ & $12(6.2)$ & $0.0004^{*}$ & $0.02^{*}$ \\
\hline HMSE & $12.71 \pm 7.60$ & $14.19 \pm 8.19$ & $30 \pm 1$ & $30 \pm 1$ & $<0.0001^{++}$ & $<0.0001^{++}$ \\
\hline EASI & $8.41 \pm 2.76$ & $8.19 \pm 3.03$ & 0 & 0 & $<0.0001^{++}$ & $<0.0001^{++}$ \\
\hline $\mathrm{E} 2 \mathrm{E} 2, n(\%)$ & $0(0)$ & $1(0.8)$ & $0(0)$ & $0(0)$ & $1^{+}$ & $0.39^{+}$ \\
\hline $\mathrm{E} 2 \mathrm{E} 3, n(\%)$ & $11(5.3)$ & $11(9)$ & $5(7.1)$ & $23(11.9)$ & $0.017^{*}$ & $0.42 *$ \\
\hline $\mathrm{E} 3 \mathrm{E} 3, n(\%)$ & $100(47.8)$ & $82(67.2)$ & $48(68.6)$ & $138(71.5)$ & $<0.0001^{*}$ & $0.42 *$ \\
\hline $\mathrm{E} 2 \mathrm{E} 4, n(\%)$ & $13(6.2)$ & $4(3.3)$ & $0(0)$ & $2(1)$ & $0.007^{+}$ & $0.21^{+}$ \\
\hline $\mathrm{E} 3 \mathrm{E} 4, n(\%)$ & $71(34)$ & $22(18)$ & $16(22.9)$ & $30(15.5)$ & $<0.0001^{*}$ & $0.56^{*}$ \\
\hline $\mathrm{E} 4 \mathrm{E} 4, n(\%)$ & $14(6.7)$ & $2(1.6)$ & $1(1.4)$ & $0(0)$ & $0.0001^{+}$ & $0.15^{+}$ \\
\hline Total ApoE4 carrier, $n(\%)$ & $98(46.9)$ & $28(23)$ & $17(24.3)$ & $32(16.6)$ & $<0.0001^{*}$ & $0.16^{*}$ \\
\hline ApoE4 carrier with DM, $n(\%)$ & $20(9.6)$ & $4(3.3)$ & $0(0)$ & $2(1)$ & $0.0001^{+}$ & $0.21^{+}$ \\
\hline
\end{tabular}

HMSE: Hindi Mental Status Examination (indicates level of cognitive function; highest score possible $=31$ ). EASI: Everyday Abilities Scale for India (indicates level of functional disability, highest score possible $=12$ ). $P$ values calculated by unpaired $t$-test ${ }^{++}$, chi-square test ${ }^{*}$, and Fisher's exact test ${ }^{+}$.
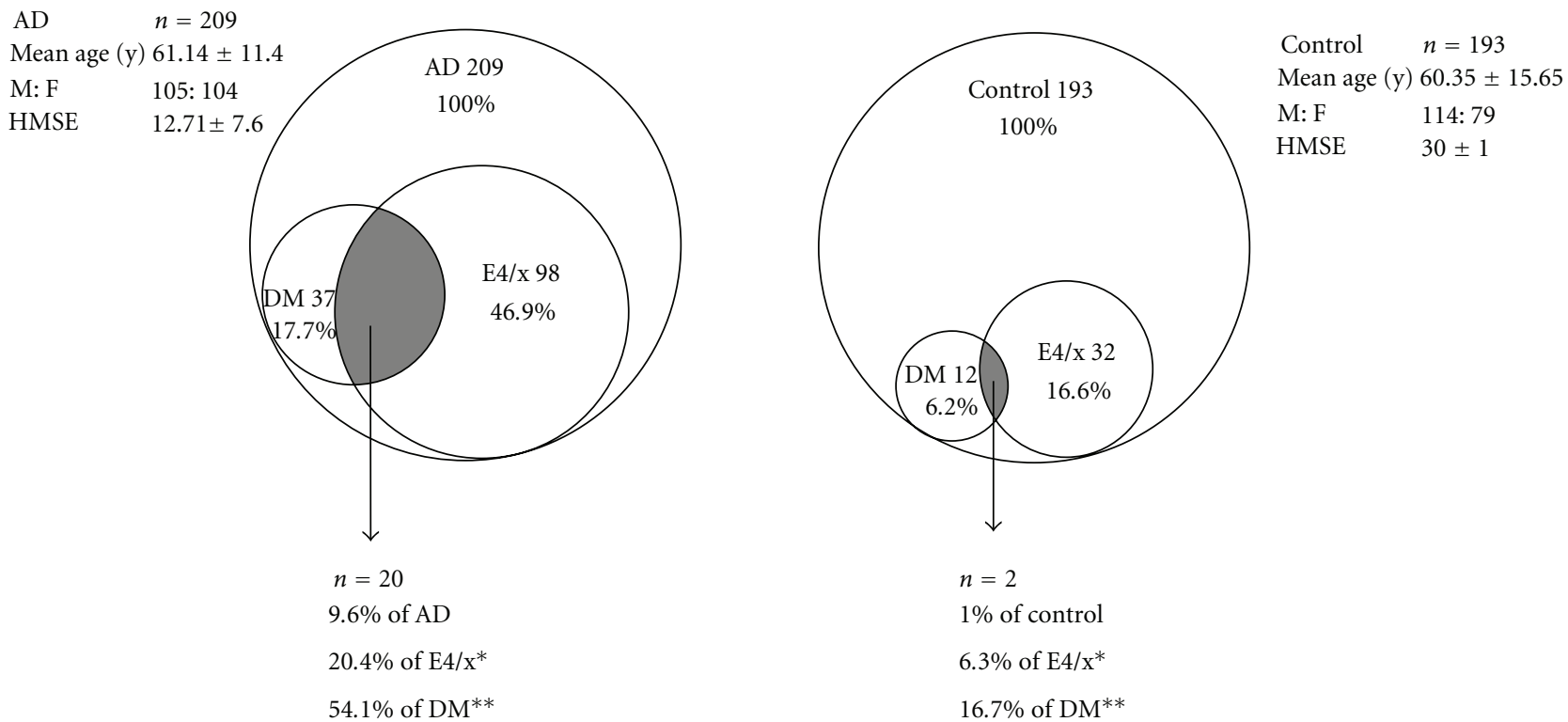

FIgURE 1: Venn diagram representation of $\mathrm{AD}$ and controls with their component distribution. Odds ratio comparing DM occurrence in ApoE4 carriers between $\mathrm{AD}$ and controls is $3.85\left(P=0.1^{*}\right)$. Odds ratio comparing ApoE4-positive $\mathrm{DM}$ subjects between $\mathrm{AD}$ and controls is $5.68\left(P=0.04^{* *}\right)$.

Lack of prospective design, detailed assessment of DM and other validating phenotypes of $\mathrm{AD}$ like neuropsychological assessment, and imaging techniques for all the subjects are the limitations of the study. Reasonable sample size, methodological rigor in diagnostic assessment, and an attempt to correlate two conditions of increasing concern in
India, that is, diabetes and $\mathrm{AD}$ in the context of ApoE4 allele are the strengths of the work.

Translational aspect of this association if proven is very important. In the Indian context, prevalence of diabetes is on the rise. Lifestyle and diet control measures to prevent DM in ApoE4-positive individuals especially with homozygosity 
in middle age may modify/reduce the risk of Alzheimer's dementia.

\section{Acknowledgments}

The study was supported by grants received from the Indian Council of Medical Research and Department of Biotechnology, India. The authors acknowledge Mr. Muralidharan Jayaraman for DNA isolation. They would like to thank Dr. Mariamma Philip, Department of Biostatistics, for suggestions on statistical analysis.

\section{References}

[1] K. S. Shaji, A. T. Jotheeswaran, N. Girish et al., "The dementia India report: prevalence, impact, costs and services for dementia: executive summary," Alzheimer's \& Related Disorders Society of India, pp. 1-38, 2010.

[2] S. Bharath, M. Purushottam, O. Mukherjee et al., "Apolipoprotein e polymorphism and dementia: a hospital-based study from southern India," Dementia and Geriatric Cognitive Disorders, vol. 30, no. 6, pp. 455-460, 2011.

[3] S. Kapur, S. Sharad, M. Kapoor, and K. Bala, "ApoE genotypes: risk factor for Alzheimer's disease," Journal, Indian Academy of Clinical Medicine, vol. 7, no. 2, pp. 118-122, 2006.

[4] G. R. Chandak, M. U. Sridevi, C. J. Vas, D. M. Panikker, and L. Singh, "Apolipoprotein E and presenilin-1 allelic variation and Alzheimer's disease in India," Human Biology, vol. 74, no. 5, pp. 683-693, 2002.

[5] M. Ganguli, V. Chandra, M. I. Kamboh et al., "Apolipoprotein E polymorphism and Alzheimer disease: the Indo-US crossnational dementia study," Archives of Neurology, vol. 57, no. 6, pp. 824-830, 2000.

[6] International Diabetes Federation, Diabetes Atlas, International Diabetes Federation, 3rd edition, 2006.

[7] V. Radha and V. Mohan, "Genetic predisposition of type 2 diabetes among Asian Indians," Indian Journal of Medical Research, vol. 125, no. 3, pp. 259-274, 2007.

[8] J. Kuusisto, K. Koivisto, L. Mykkanen et al., "Association between features of the insulin resistance syndrome and Alzheimer's disease independently of apolipoprotein E4 phenotype: cross sectional population based study," British Medical Journal, vol. 315, no. 7115, pp. 1045-1049, 1997.

[9] T. Ohara, Y. Doi, T. Ninomiya et al., "Glucose tolerance status and risk of dementia in the community," Neurology, vol. 77, no. 12, pp. 1126-1134, 2011.

[10] W. Xu, C. Qiu, B. Winblad, and L. Fratiglioni, "The effect of borderline diabetes on the risk of dementia and Alzheimer's disease," Diabetes, vol. 56, no. 1, pp. 211-216, 2007.

[11] Z. Arvanitakis, R. S. Wilson, J. L. Bienias, D. A. Evans, and D. A. Bennett, "Diabetes mellitus and risk of Alzheimer disease and decline in cognitive function," Archives of Neurology, vol. 61, no. 5, pp. 661-666, 2004.

[12] A. Ott, R. P. Stolk, F. van Harskamp, H. A. P. Pols, A. Hofman, and M. M. B. Breteler, "Diabetes mellitus and the risk of dementia: the Rotterdam study," Neurology, vol. 53, no. 9, pp. 1937-1942, 1999.

[13] C. L. Leibson, W. A. Rocca, V. A. Hanson et al., "Risk of dementia among persons with diabetes mellitus: a populationbased cohort study," American Journal of Epidemiology, vol. 145, no. 4, pp. 301-308, 1997.
[14] C. MacKnight, K. Rockwood, E. Awalt, and I. McDowell, "Diabetes mellitus and the risk of dementia, Alzheimer's disease and vascular cognitive impairment in the Canadian Study of Health and Aging," Dementia and Geriatric Cognitive Disorders, vol. 14, no. 2, pp. 77-83, 2002.

[15] M. Tripathi, D. Vibha, P. Gupta et al., "Risk factors of dementia in North India: a case-control study," Aging \& Mental Health, vol. 16, no. 2, pp. 228-235, 2012.

[16] R. Peila, B. L. Rodriguez, and L. J. Launer, "Type 2 diabetes, APOE gene, and the risk for dementia and related pathologies: the Honolulu-Asia Aging study," Diabetes, vol. 51, no. 4, pp. 1256-1262, 2002.

[17] T. Matsuzaki, K. Sasaki, Y. Tanizaki et al., "Insulin resistance is associated with the pathology of Alzheimer disease: the Hisayama study," Neurology, vol. 75, no. 9, pp. 764-770, 2010.

[18] G. G. Fillenbaum, V. Chandra, M. Ganguli et al., "Development of an activities of daily living scale to screen for dementia in an illiterate rural older population in India," Age and Ageing, vol. 28, no. 2, pp. 161-168, 1999.

[19] M. Ganguli, G. Ratcliff, V. Chandra et al., "A Hindi version of the MMSE: the development of a cognitive screening instrument for a largely illiterate rural elderly population in India," International Journal of Geriatric Psychiatry, vol. 10, no. 5, pp. 367-377, 1995.

[20] S. A. Miller, D. D. Dykes, and H. F. Polesky, "A simple salting out procedure for extracting DNA from human nucleated cells," Nucleic Acids Research, vol. 16, no. 3, article 1215, 1988.

[21] P. Pantelidis, M. Lambert-Hammill, and A. S. Wierzbicki, "Simple sequence-specific-primer-PCR method to identify the three main apolipoprotein E haplotypes," Clinical Chemistry, vol. 49, no. 11, pp. 1945-1948, 2003.

[22] J. Fox, "The R commander: a basic-statistics graphical user interface to R," Journal of Statistical Software, vol. 14, no. 9, pp. 1-42, 2005.

[23] M. D. Shriver, E. Boerwinkle, D. Hewett-Emmett, and C. L. Hanis, "Frequency and effects of apolipoprotein E polymorphism in Mexican-American NIDDM subjects," Diabetes, vol. 40, no. 3, pp. 334-337, 1991. 


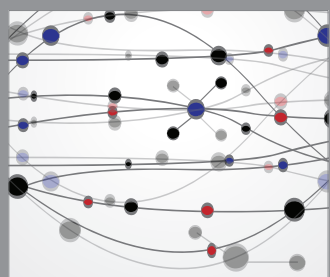

The Scientific World Journal
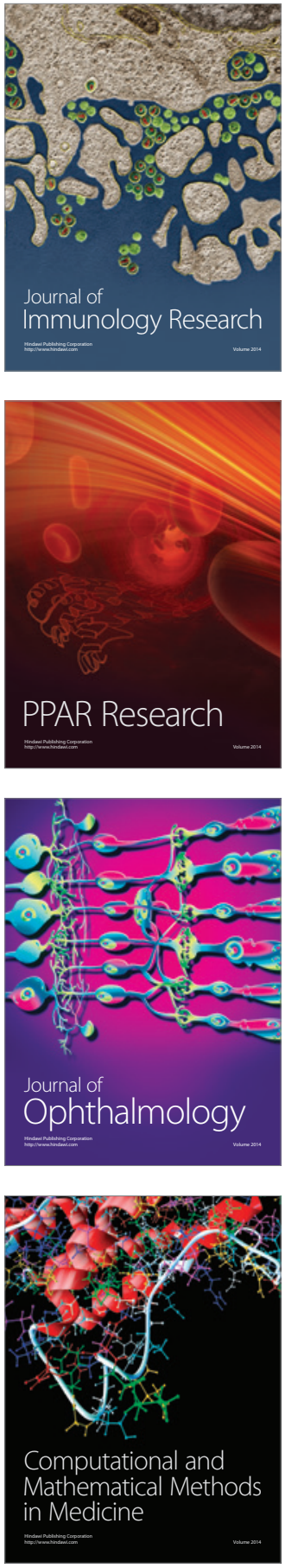

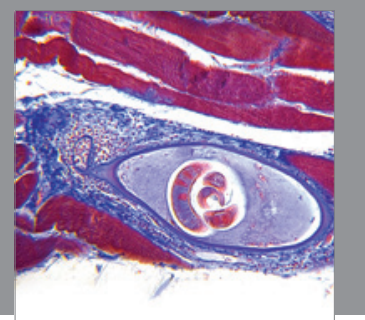

Gastroenterology

Research and Practice
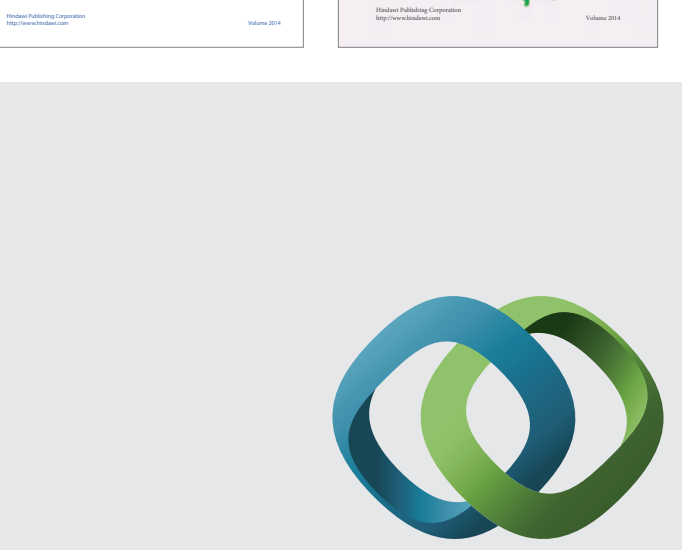

\section{Hindawi}

Submit your manuscripts at

http://www.hindawi.com
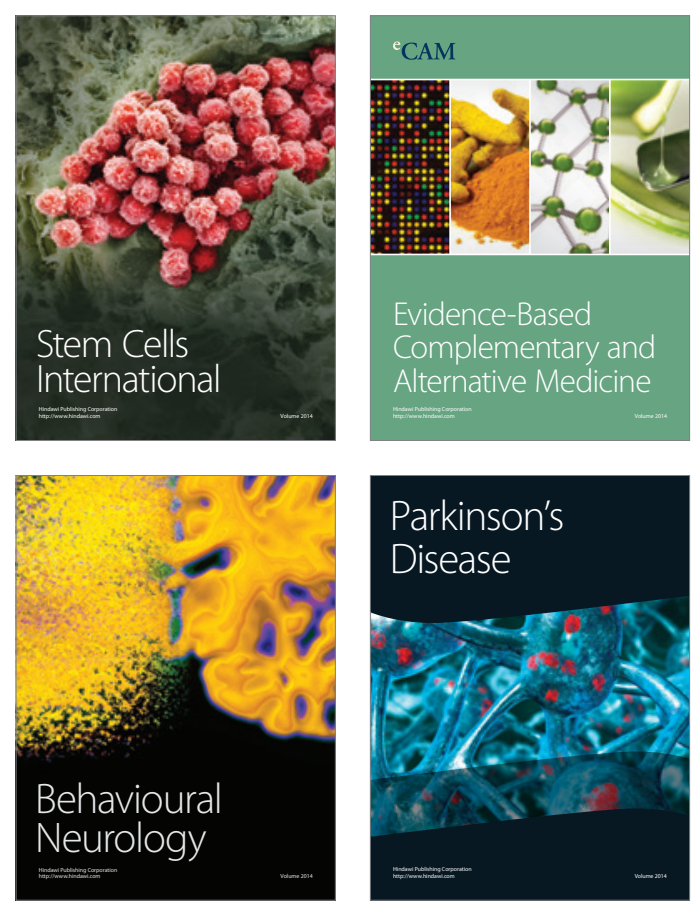

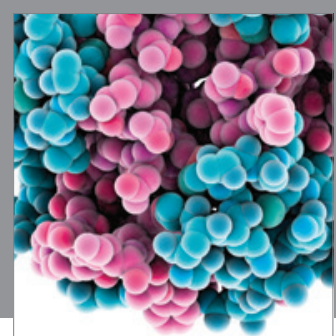

Journal of
Diabetes Research

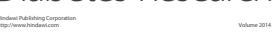

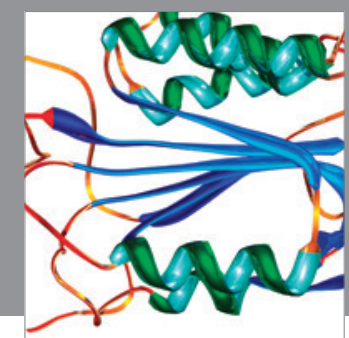

Disease Markers
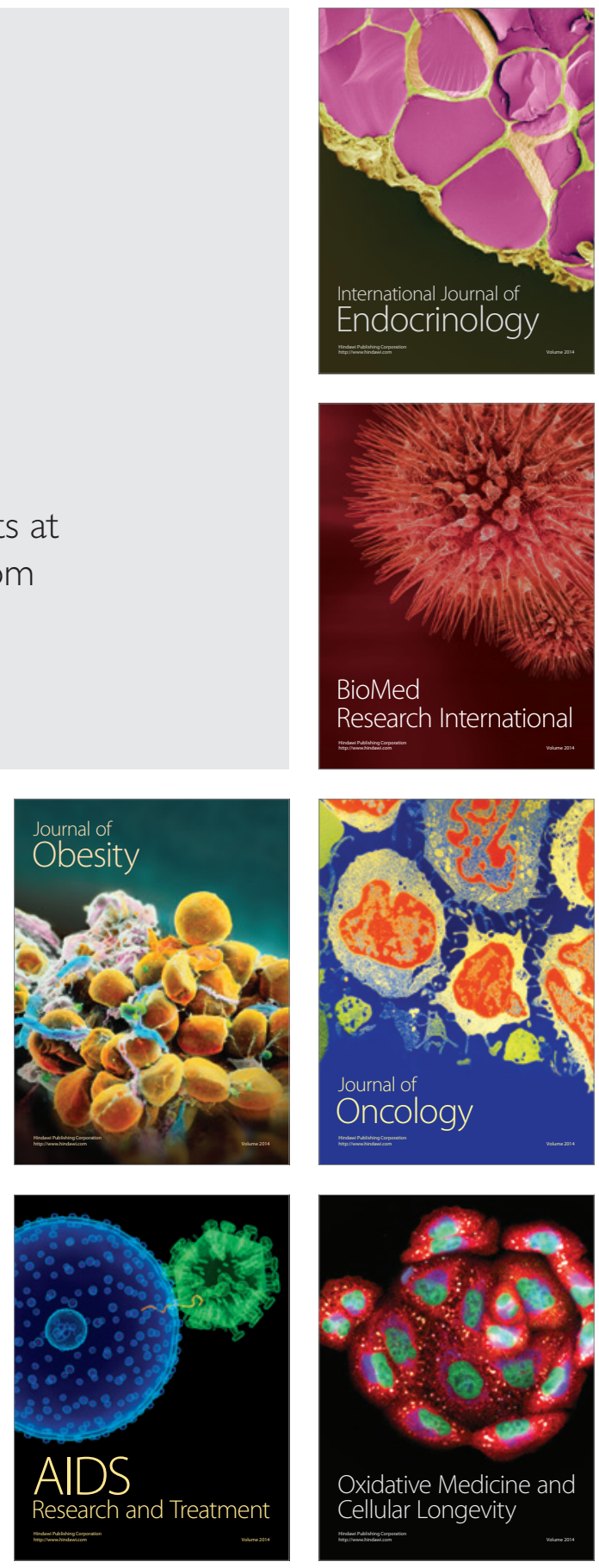